\title{
First Class Rail in Switzerland: The effect of a two-tier ticket structure on energy use
}

2017 - University of Geneva

\author{
Simon Perdrisat \\ perdrisat@gmail.com \\ https://orcid.org/0000-0002-2437-0386 \\ https://doi.org/10.31235/osf.io/d7yqt
}




\section{First Class Rail in Switzerland: The effect of a two-tier ticket structure on energy use}

This paper explores whether SBB can spare energy by renouncing its first class. SBB currently offers two classes on intercity trains. A first-class ticket is twice the price of the second-class ticket for the same travel. The first-class passenger cars have a lower number of seats and potentially different occupancy. Through different scenarios, we will analyse how this difference in price and seat density between the first and second classes can affect the energy consumption by people transported on the intercity line between Zurich and Geneva.

In 2015 transportation in Switzerland was responsible for $36.4 \%$ of the total use of final energy and $43 \%$ of $\mathrm{CO} 2$ emission. ${ }^{1}$ The country has an extensive rail infrastructure operated by $\mathrm{SBB}^{2}$. Electricity consumed in Switzerland comes from its own production by nuclear and hydraulic power plants. During summer, there is a surplus that is exported but some electricity has to be imported during winter. Those importations come from France (nuclear) and Germany (gas, coal, and others). ${ }^{3}$

SBB produce $75 \%$ of their electricity used by the traction. This production is $75 \%$ from renewable energy with low $\mathrm{CO} 2$ emissions, and they target $100 \%$ renewable production by 2025. ${ }^{4}$ Therefore, it seems to be an important mode of transportation to mitigate climate change.

On the $36.4 \%$ of energy used in transportation, only $4 \%$ is used by rail. Rail transport $17 \%$ of people.

But still SBB is using significant amounts of electricity which, if its efficiency can be improved, could be used elsewhere or spared. As noted above, Switzerland has to import massive amount of electricity from France, equivalent to two nuclear plants like Gösgen. France's nuclear power plants are often criticized by the population and politicians alike and their safety and future does not seem to be assured. In this context, saving electricity seems rational.

\footnotetext{
1 "Statistique Globale Suisse de l'énergie 2015."

${ }^{2} \mathrm{SBB}$ is the german abreviation. The french one is CFF and italien is FFS. We will keep SBB for simplicity.

3 "Statistique Suisse de l'électricité 2015," 6.

${ }^{4}$ SBB, "Stratégie Énergétique Des CFF: Nous Optons Pour Un Courant de Traction Provenant à 100\% d'énergies Renouvelables."
} 


\section{Case: Geneva to Zurich, Monday 17:42}

Throughout this work the IC731 living Geneva 18 December 2016 (Monday) at 17:42 to Zurich was used for calculation. This train was chosen because it crosses the country and therefore a lot of people know this journey. It also seems one of the most representative journeys of the average IC in Switzerland. The time is not rush hours, but kind of crowded and occupancy change over time which is perfect to explain the chosen methodology.

\section{Occupancy}

Occupancy is key to find the efficiency of a given mode of transport. ${ }^{5}$ In the short term, the marginal energy cost of one passenger is virtually zero. This is because a passenger is extremely light in comparison of a train car. On average, long distant train weight 326 tonnes. The extra $80 \mathrm{~kg}$ of an extra passenger is therefore not relevant for energy consumption. ${ }^{6}$ In the short run, the train will run with or without this passenger. As we see a train car is very heavy, therefore, an extra train car will require a lot of energy to be moved. On top of that train car needs energy for heating and maintenance (temperature management is not marginal and counts for around $25 \%$ of the energy).

SBB refuse to provide access to their occupancy data. Therefore, occupancy was extrapolated from SBB's online timetable. Those data are publicly available and cover all possible journey. But as we will see, they are not very precise and only give a general view. Another way to explore would be to use their online calculator ${ }^{7}$ for internal advertising.

\footnotetext{
${ }^{5}$ Tuchschmid, "SBB Ecocalculator."

${ }^{6}$ Tuchschmid, 4.

7 Internal advertising online calculator: http://www.sbb.ch/en/group/sbb-as-businesspartner/railadvertising/in-the-train/railposterrailmidiposter/online-calculator.html
} 
The online timetable use pictograms to inform passengers of the occupancy of the train (see Figure 1).

\section{2. i}

Figure 1 SBB occupancy pictogram

Those pictograms represent low, medium and high occupancy. The SBB Eco calculator let us know what is behind those pictograms ${ }^{8}$ :

- Low occupancy: $10 \%$ of seats are occupied

- Medium occupancy: $50 \%$ of seats are occupied

- High occupancy: $100 \%$ of seats are occupied

It should be noted that occupancy can be higher than $100 \%$ when there is not enough seat for every passenger. But occupancy higher than $100 \%$ is not reported on the SBB online timetable.

It is also worth mentioning that the average occupancy depends on the mode of transport, e.g. $33 \%$ for a long-distance train.

The SBB website gives us information about the occupancy by section (Figure 2). From this data we can find the weighted arithmetic mean using occupancy and the travel time from each section. Using this method, first class occupancy weighted means is 0.1 and second class occupancy weighted mean is 0.54 for this journey.

Why not use distance instead of time? In fact, neither distance nor time is precise, there are a lot of factors that can affect energy consumption, mainly maximum speed, the weight of the train and stopping patterns. ${ }^{9}$ Also, have we had seen moving the train is not the only energy heating and lighting is not negligible. I choose time because the data was available on their website and it's highly correlated with distance. Because of these points, the distance does not

\footnotetext{
${ }^{8}$ Tuchschmid, "SBB Ecocalculator," 10.

${ }^{9}$ Transport Research Laboratory et al., "Methodology for Calculating Transport Emissions and Energy Consumption," 221.
} 
seem to give us a clearer picture. To have precise energy consumption should be measured directly on the train, but again SBB is not interested in providing those kinds of data.

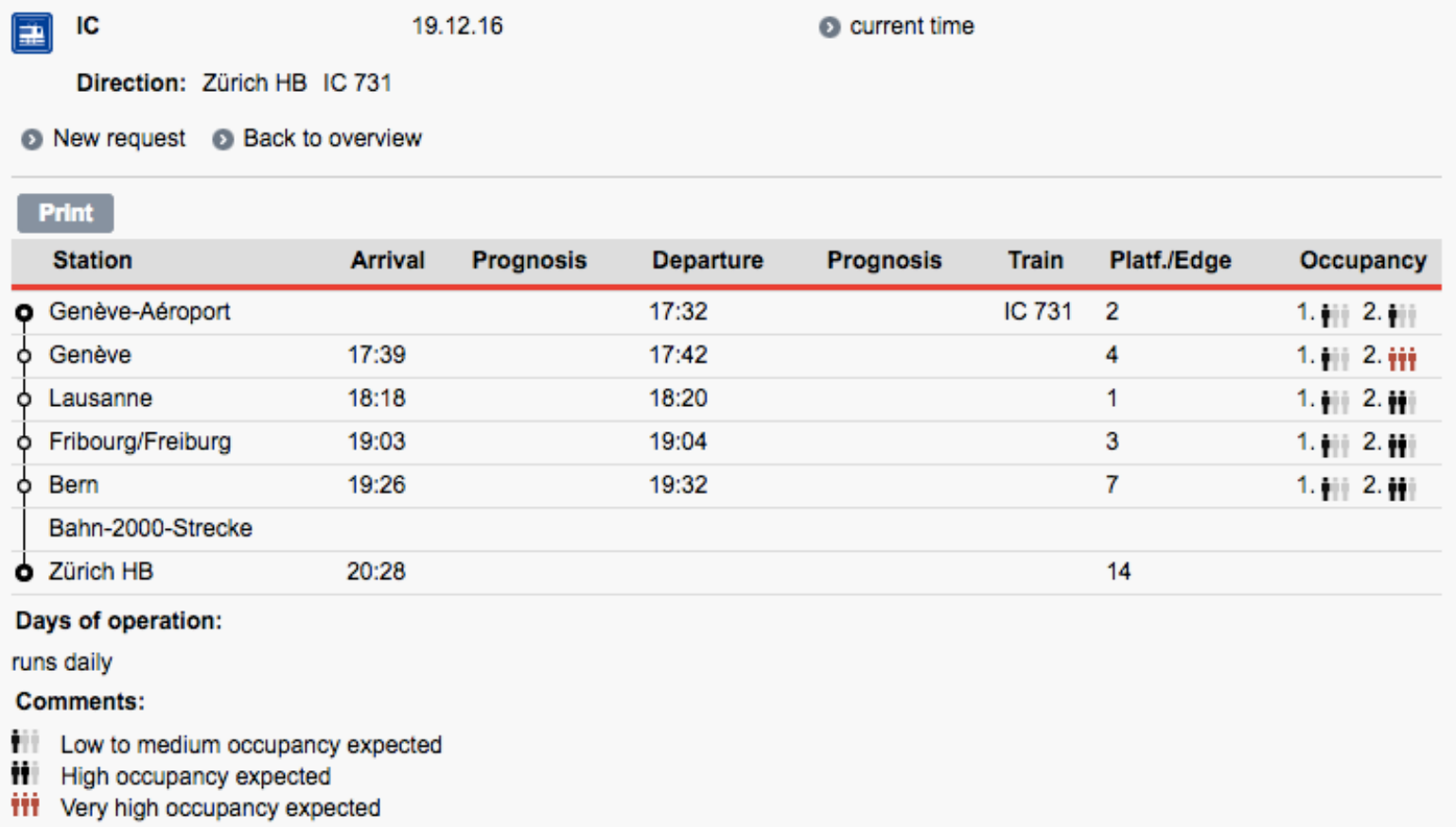

Figure 2 Occupancy by sections from $S B B$ website

\section{From occupancy to efficiency}

Passenger cars from this train (IC - Rail 2000) are two-floor cars. The $1^{\text {st }}$ class car has 86 seats and the $2^{\text {nd }} 128 .{ }^{10}$ From the mobile app you can know the composition of a given train. This one is like that (each [] represent a train car):

$\left[1^{\mathrm{st}}\right]-\left[1^{\mathrm{st}}\right]-[$ traction $]-\left[1^{\mathrm{st}}\right]-\left[1^{\mathrm{st}}\right]-[$ Restaurant $]-\left[2^{\text {nd }}\right]-\left[2^{\text {nd }}\right]-\left[2^{\text {nd }}\right]-\left[2^{\text {nd }}\right]-[$ Family and bicycle $]$

As you can see there are four $1^{\text {st }}$ class cars, four $2^{\text {nd }}$ class cars, one restaurant car, and one family and bicycle car. I choose to exclude the restaurant and family bicycle cars. Both cars have a low seat density and are used to access SBB services (children space, bicycle space and restoration). The restaurant car is definitely used by passengers from $1^{\text {st }}$ and $2^{\text {nd }}$. Finally, if we imagine a train without $1^{\text {st }}$ class, those two special cars will still be needed.

${ }^{10}$ SBB, "IC2000." 
So now we can calculate the total seats in this train for each class by multiplying the car seat by the total cars:

$$
\begin{aligned}
& 1 \text { st class total seat }=4 * 86=344 \text { seats } \\
& 2 n d \text { class total seat }=4 * 128=512 \text { seats }
\end{aligned}
$$

We can already know the efficiency difference in percentage if both classes have a full occupancy (all seats taken). From this hypothetical situation, we can calculate than the $2^{\text {nd }}$ class is $48 \%$ more efficient.

$$
\frac{512-344}{344}=0.48
$$

So now let's take the class occupancy we found earlier for this train. This show than the $2^{\text {nd }}$ is $70 \%$ more efficient or if you prefer the $1^{\text {st }}$ class is $87 \%$ less efficient for this journey.

$$
\begin{aligned}
& \frac{512 * 0.54-344 * 0.1}{344 * 0.1}=0.70 \\
& \frac{344 * 0.1-512 * 0.54}{512 * 0.54}=-0.87
\end{aligned}
$$

We can also find the average occupied seats by using the average occupancy and the total set.

$$
1 \text { st class average occupied seat }=344 * 0.1=34.4
$$

2 nd class avergage occupied seats $=512 * 0.54=276.48$

This clearly shows than the $1^{\text {st }}$ class is inefficient because it has a lower density of seats by car and because it has a lower occupancy rate. These two effects add up and explain those huge differences between $1^{\text {st }}$ and $2^{\text {nd }}$ class.

\section{Difference in Profit}

A $1^{\text {st }}$ class ticket is more expensive for the same journey, twice the amount of the $2^{\text {nd }}$ class. But the $1^{\text {st }}$ class does not generate a higher profit than the $2^{\text {nd }}$ class. We don't know when people get on or off the train, therefore it's impossible to know how much they pay. We also have to 
keep in mind that there are different prices. There is for example half-price card, GA travel card, price for under 16, group, and so one.

But we can use the price $P$ for the $2^{\text {nd }}$ class and $2 P$ for the first and see what appends for the journey we study earlier.

$$
\begin{gathered}
\text { profit } 1 \text { st class }=1 \text { st class average occupied seat } * 2 P=34.4 * 2 P=68.8 P \\
\text { profit } 2 \text { nd class }=2 n d \text { class avergage occupied seats } * P=276.48 * P=276.48 P
\end{gathered}
$$

The $1^{\text {st }}$ class is less profitable than the $2^{\text {nd }}$ class. We can also graph (figure 3 ) the total revenue for each class depending of the $2^{\text {nd }}$ ticket price.

Total revenu by class

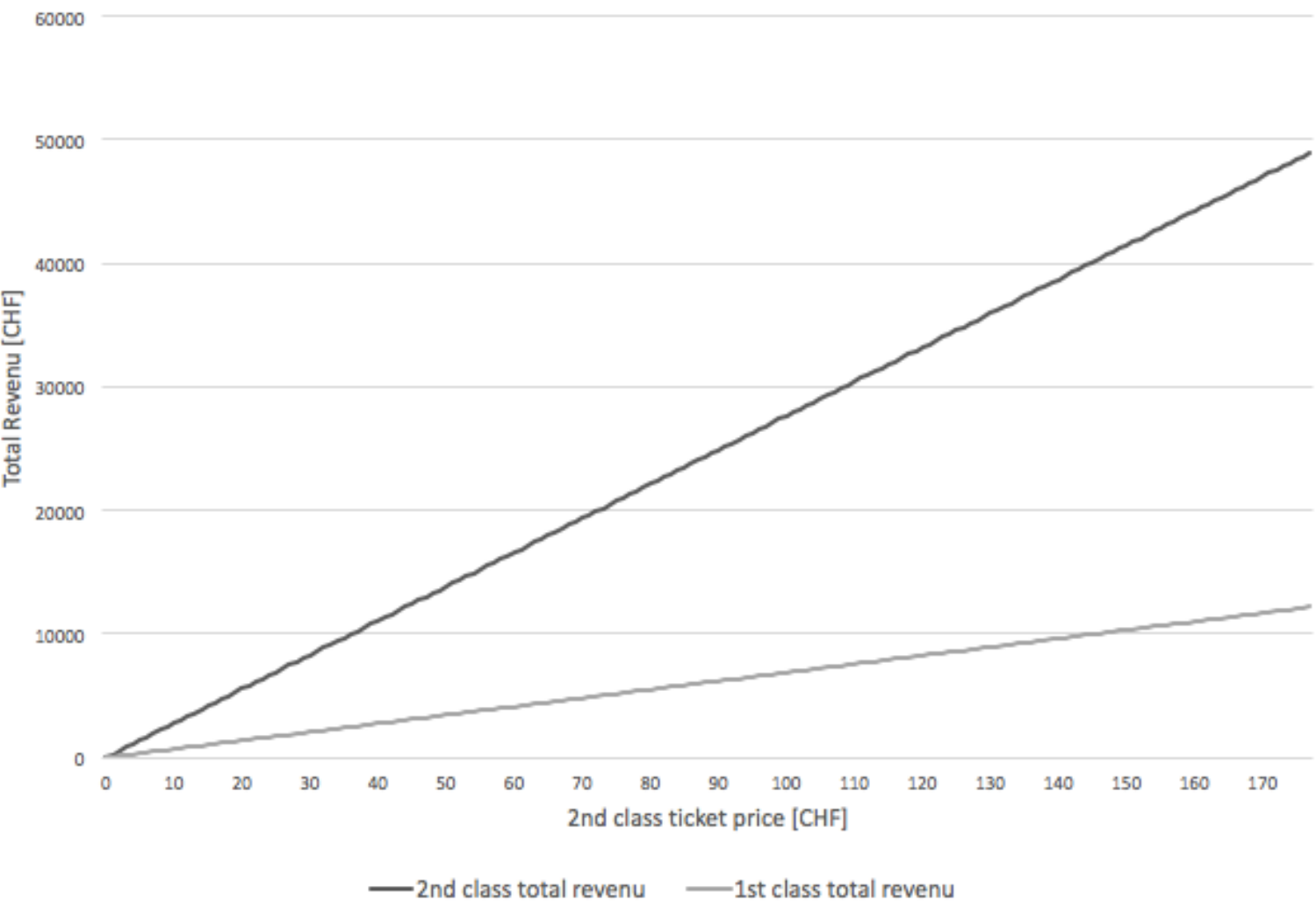

Figure 3 Total revenue by class

\section{Marginal effect of an extra passenger}

What appends if we distribute the total energy used by a train to every passenger? As we can see in figure 4, the individual passenger's share quickly declines. If we have a train we only one passenger, it will use $100 \%$ of the energy. If you add an extra passenger, this will be $50 \%$ 
and $33.3 \%$ for three. If we take only the $2^{\text {nd }}$ class and every 512 seats are taken, each passenger consumes only $0.20 \%$ of the total energy. For the first class if all 344 seats are taken its $0.29 \%$.

But with an average of 34 seats occupied by the $1^{\text {st }}$ class it's $2.94 \%$. For the $2^{\text {nd }}$ class with an average of 276 seats occupied is $0.35 \%$. That means a $1^{\text {st }}$ passenger in this scenario consume on average 8 times more energy than the $2^{\text {nd }}$ one.

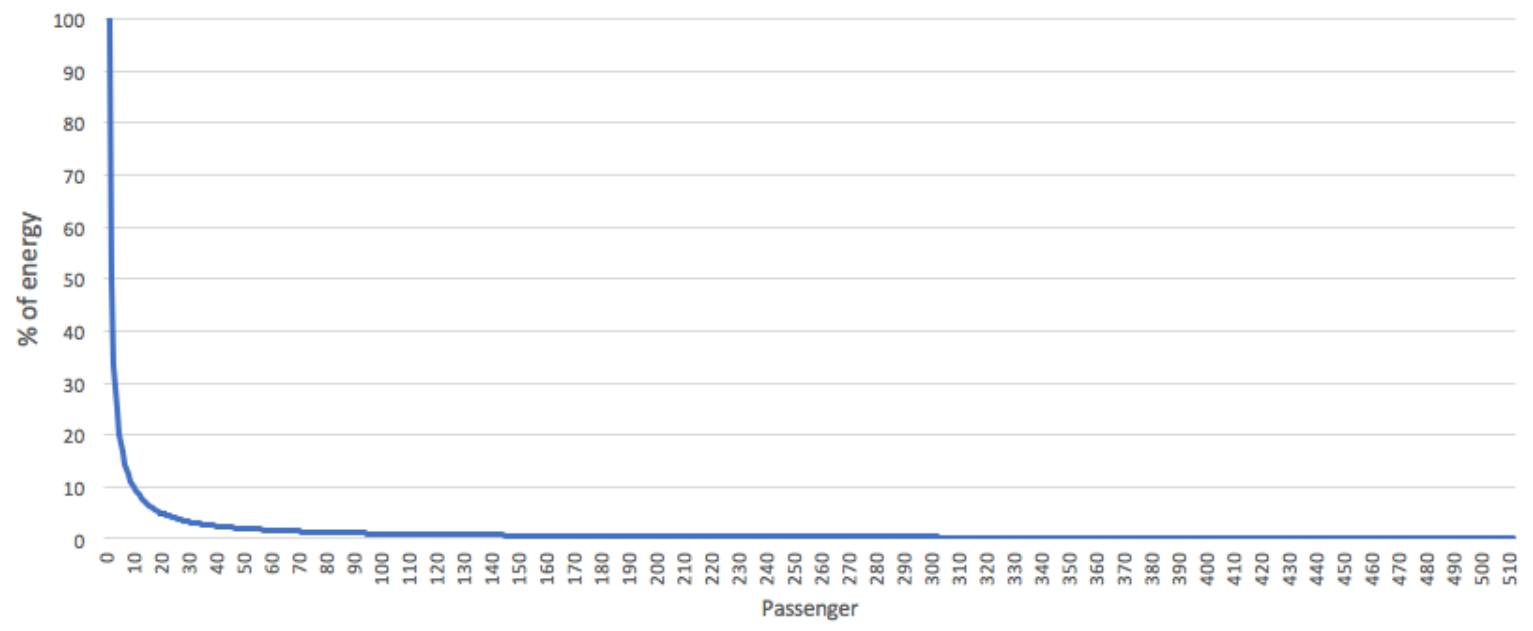

Figure 4 Energy by passengers

Figure 4 clearly illustrates than energy usage by passengers is reduced dramatically with higher occupancy. That means than the energy cost of an extra passenger become very low. This should be a major incentive to try to have the highest occupancy possible.

\section{Life Cycle Assessment (LCA)}

In this study, we only considered the direct energy needed by the train for a given travel. But to have the whole picture one should take a life cycle assessment ${ }^{11}$ approach to consider the energy needed to build the cars, store, clean and eliminate them. For example, SBB is currently planning to build longer platforms in Lausanne train station and other cities. Those

${ }^{11}$ ISO 14040:2006 Environmental management - Life cycle assessment - Principles and framework define LCA has "compilation and evaluation of the inputs, outputs and the potential environmental impacts of a product system throughout its life cycle" and life cycle "consecutive and interlinked stages of a product system, from raw material acquisition or generation from" 
transformations would have perhaps not been needed without $1^{\text {st }}$ class or at least not now. This is simple, if you have a higher density of seats by train you need smaller trains to transport the same number of people. That means less car, smaller train station, smaller train storage: virtually everything's is scaled down. Of course, this reduction is not proportional to the percentage of change in density because economies of scale need to be considered.

\section{Political Implications}

SBB used to be fully managed by government, but since 1999 it's a private enterprise whose shares are held by the Confederation or Cantons. ${ }^{12}$ The Confederation is obligated to keep more than half of the share.

Numerous commuters depend on this mode of transport, and price change is a sensitive subject. Because this market has no direct concurrence, price is regularly examined by the Confederation's “price monitoring” service.

SBB is not a regular private company, but a private company mandated by the Confederation. The Federal Conceal define strategic objectives every 4 years that the Confederation want to reach for SBB has the owner of the company.

It seems that 1 st class is less efficient and not as profitable than the $2^{\text {nd }}$ class. If those results are confirmed, this should trigger different possible political responses from the government and SBB. It would not be socially and politically acceptable that passengers in $2^{\text {nd }}$ class are paying a higher share than the $1^{\text {st }}$ class. It's also not acceptable than the $1^{\text {st }}$ class reduce the SBB global efficiency and economic profitability.

Depending on price elasticity, increasing the price to make a $1^{\text {st }}$ class passenger pay the cost of the service they use is a possibility. This approach does not maximize energy efficiency has $1^{\text {st }}$ class will still have a lower occupancy and density.

Decreasing the $1^{\text {st }}$ class seems rational. If $1^{\text {st }}$ class cars were full or almost full, it would be more profitable than $2^{\text {nd }}$ class. But a given train can't change his configuration easily during a

${ }^{12}$ Confédération suisse, "Loi sur les Chemins de fer fédéraux." 
day. So, if on a small portion there is a huge demand for $1^{\text {st }}$ class but nothing for the rest of the journey, the average occupancy will still be very low.

Completely removing the $1^{\text {st }}$ class is the most ecological option. First-class cars should be left with their current design to avoid extra costs but it will instantly increase the $2^{\text {nd }}$ class capacity, making public transportation more attractive for most of the passengers. But mainly, trains will be composed of fewer cars, reducing energy usage.

At a first step, the government should ask for more transparency. This issue needs access to precise and clear data about occupancy. Those data are obviously available and should be made public. Then an informed and democratic discussion can happen.

\section{Conclusion}

Generally, train is seen as an environmentally friendly transportation, but resources are still wasted if efficiency can be improved with almost no capital investment by changing price structure and/or $1^{\text {st }}$ class seats quantity. As most $1^{\text {st }}$ class seats are unoccupied, the $2^{\text {nd }}$ class passengers have to bear the cost of the $1^{\text {st }}$ class and the train global efficiency is reduced drastically.

Transport efficiency shouldn't only be compared with other transportation modes, and more precisely, cars should not be used as the only reference point.

Finally, transparency from SBB is needed so further and more precise research can be done.

\section{Open Access}

This article is distributed under the terms of the Creative Commons Attribution 4.0 International License (https://creativecommons.org/licenses/by/4.0/), which permits unrestricted use, distribution, and reproduction in any medium, provided you give appropriate credit to the original author(s) and the source, provide a link to the Creative Commons license, and indicate if changes were made.

\section{References}

Confédération suisse. "Loi sur les Chemins de fer fédéraux," January 1, 2016. https://www.admin.ch/opc/fr/classified-compilation/19983388/index.html.

SBB. “IC2000.” sbb, -. http://www.sbb.ch/sbb-konzern/ueber-die-sbb/rollmaterial/ic2000.html.

"Stratégie Énergétique Des CFF: Nous Optons Pour Un Courant de Traction Provenant à 100\% d'énergies Renouvelables." Service de presse CFF, 2015.

“Statistique Globale Suisse de l'énergie 2015.” Office Fédéral de L’énergie OFEN, 2015.

“Statistique Suisse de l'électricité 2015.” Office Fédéral de L’énergie OFEN, 2015.

Transport Research Laboratory, J Hickman, D Hassel, R Joumard, Z Samaras, and S Sorenson. "Methodology for Calculating Transport Emissions and Energy Consumption.” Transport Research Laboratory, 1999. 
Tuchschmid, Mathias. "SBB Ecocalculator,” October 17, 2011. 